\title{
The impact of the World Military Games on the COVID-19 pandemic
}

\author{
Amy Elise Winter ${ }^{1}$ \\ Received: 8 December 2020 / Accepted: 16 December 2020 / Published online: 19 January 2021 \\ (C) Royal Academy of Medicine in Ireland 2021
}

It is clear that travel was a major factor in the rapid dissemination of COVID-19 disease. It has been proposed that Wuhan, China, was the epicentre of the pandemic. The World Military Games took place from the $18^{\text {th }}$ to $27^{\text {th }}$ of October 2019 in Wuhan, China. Over 140 nations with 9308 athletes participated with over 300,000 attendees, volunteers and staff [1-4]. This study examined the hypothesis that the large gathering in a pandemic epicentre was a factor in the spread of COVID-19 disease.

The data on the number of athletes and the number of COVID-19 cases per country were extracted from internet sources [1-4] and were examined from a European perspective. Figure 1 displays the graphical plot of the number of athletes per country against the number of cases of COVID19 in that country. Note the strong correlation between these variables indicated by the curve fit and regression analysis.

From these data, the following equation can be derived:

$N_{\text {predicted }}=X(4 y)^{2}$

where $N_{\text {predicted }}=$ the total number of predicted COVID-19 cases, $X=$ the country-specific coefficient, $y=$ the number of athletes per country, and $4 y=$ the number of infected people. The $y$ is multiplied by 4 based on a viral transmission rate (R- rate) of 3 (i.e. each infected traveller infects 3 others). This was squared because each group of infected individuals infects others with at least one cycle. The median country-specific coefficient $(X)$ in Europe is 1.7 with a range of $0.1-71$ (Portugal is an outlier with the latter number-most values are under 5). Some geographically linked countries have broadly equivalent coefficients. For example, Finland, Sweden, Denmark and Norway (0.3-1.3) are similarly valued. France, Germany, Poland and Switzerland (0.3-1) are another example. Finally, Bosnia/Herzegovina and Croatia are 12.4 16.5 but curiously although they are neighbouring these countries, Austria, Slovenia, and Hungary have much lower, if homogenous, values $(0.7-1.7)$. The total $N_{\text {predicted }}$ for 31 European countries with athletes that attended the games is $4,579,102$ (as it stands, this figure is 4,370,000 - one year on from the date of the World Military Games).

There is a correlation between the number of individuals who travelled to the event and the number of COVID-19 cases in the country to which they returned. Whether this explains the rapid spread of the pandemic or not is not known definitively. However, this study shows a mathematical model to predict the number of COVID-19 cases in a country as a result of each infected individual travelling to that country.

Amy Elise Winter

winteramyelise@gmail.com

1 Mount Anville, Dublin D14A8P3, Ireland 
Fig. 1 Graphical plot of the number of athletes on the $x$-axis

with the number of infected cases per country (in thousands) for the period October 18, 2019, to October 18, 2020.
World Miliary Games attendance and Covid-19 infection

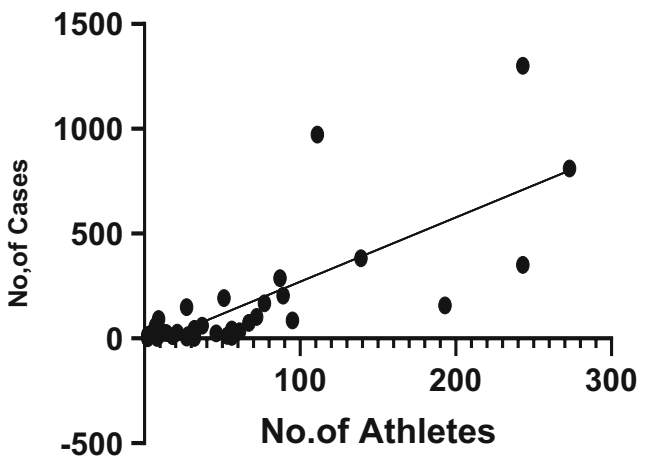

$p<0.0001$

$r=0.70$

$r^{2}=0.50$

\section{References}

4. Worldometers.info, visited on the $20^{\text {th }}$ of October 2020

1. Prospect.org, visited on the $20^{\text {th }}$ of October 2020

Publisher's note Springer Nature remains neutral with regard to jurisdictional claims in published maps and institutional affiliations. 